\title{
Cholecystectomy for Gallstone: Types and Findings
}

\author{
Hassan Abd- Rhida Atiea ${ }^{*} \quad$ Nada Saadi Majeed ${ }^{2} \quad$ Majid Abid-Saaidan $^{1}$ \\ 1.General Surgeon at Al-Kurkh Hospital. M.B.Ch.B, D.S. \\ 2.ENT Specialist at Al-Kurkh Hospital. M.B.Ch.B, D. ENT
}

\begin{abstract}
Gall stone disease remains a common and significant cause of suffering in most parts of the world. Gallstones are the most common biliary pathology. A descriptive study covered 80 patients underwent surgical treatment for gallstone diseases. Ultrasound study and plain abdominal X-ray were done to confirm the presence of gallstone. More than half of the sample 58.8\% were in the oldest age group 50-69 year. Female were 68(85\%) and the remaining $12(15 \%)$ patients were male. Most of patients $60(75.0 \%)$ operated upon by open cholecystectomy, laparoscope used in $18(22.5 \%)$. The main finding on exploring the abdomen was inflammatory adhesion in 54(67.5\%) of the patients, thick wall gallbladder came next in $12(15 \%)$ patients. Many complications and clinical findings associated with gallstone, some of them are serious other are even fatal. That is why cholecystectomy is highly indicated even for silent gallstone.
\end{abstract}

Keywords: Gallstone, Jaundice, Cholecystitis, Surgery, Laparoscopy

DOI: $10.7176 / \mathrm{JHMN} / 71-09$

Publication date: February $29^{\text {th }} 2020$

\section{Introduction:}

Gall stone disease remains a common and significant cause of suffering in most parts of the world (Balakrishnan et al. 2008). Gall stone has increasingly become a major cause of abdominal morbidity (Sachdeva et al. 2011).

The gallbladder (GB) is a pear-shaped organ, 7.5-12 cm length. It joins the common bile duct through the cystic duct at the supra-duodenal segment but there are many anatomical variations (Nagral 2005).

Bile, an aqueous solution produced and secreted by the liver, consists mainly of bile salts, phospholipids, cholesterol, conjugated bilirubin, electrolytes, and water. Bile flows into the gallbladder where it is concentrated and stored. On gallbladder contraction in response to cholecystokinin hormone, it pushing bile through the cystic duct into the common bile duct (Baiocchi et al. 2019).

The pathogenesis of GD is suggested to be multifactorial and probably develops from complex interactions between many genetic and environmental factors (Reshetnyak 2012). Cholesterol composes most gallstones, cholesterol crystal nucleation formation, and/or gallbladder motility dysfunctions (Al-Saad et al. 2018).

Gallstones are the most common biliary pathology, which can be divided into three main types: cholesterol, pigment (black, brown) or mixed stones (Singha et al. 2017). It may be single or multiple, large or small. Single stones are uncommon but usually consist mainly of cholesterol (Yousif 2011).

The role of infection in GS is unclear, the radiolucent center of many GS is representing a mucus plugs which formed around the bacteria. Gallbladder contractility is reduced by estrogen, pregnancy, truncal vagotomy result in bile stasis which increased incidence of GS. Hemolytic anemia increases incidence of pigmented GS (Sachdeva et al. 2011).

Although several studies have provided evidence supporting the role of gall bladder bile stasis in the genesis of gall stones, clear cut data on impaired gall bladder contractility have not been found consistently in gall stone patients (Cicala et al. 2011).

The classic presentation of symptomatic gallstones is a patient with recurrent right upper quadrant pain, sometimes, the initial presentation of gallstones may be acute cholecystitis, due to secondary infection. In some cases, the stone obstruct the common bile duct, causing cholestasis. Jaundice can develop (Al-Saad et al. 2018).

\section{Materials and Methods:}

A descriptive prospective study. The study covered 80 patients with gallstone diseases. All of them were operated upon for gall stones disease in AL-Najaf Teaching Hospital \& AL-Noor hospital in the period extended from January 2002 to October 2003.

Ultrasound study was done to all the patients which confirm the presence of GS, in addition it gave information about thickness of the GB wall, its size, any stone in the biliary tree, or pancreatic pathology like malignancy. Plain radiology for abdomen were done for 40 patients to explore the rate of radio-opaque gall stone, and to confirm calcified wall of GB. Finally, liver function test and general laboratory tests for patients going to submitted to general anesthesia.

Operative methods: Cholecystectomy (open or by laparoscope) were done for the patients. In some patients, laparoscopic cholecystectomy started with then ended with open cholecystectomy. All operative finding during operation recorded for all patients for possible GS complication.

Post-operative reports: Specimen were sent for histopathological examination; five cases malignancy was 
suspected macroscopically. Biochemical analysis of the removed stones from only 30 cases was performed to identify the chemical constitution of the stones. T-tube cholangiography done for (7) patients, at day tenth postoperative by injection of sodium diatrizote dye down into T-tube, before removal of T-tube to visualize the biliary tree especially common bile duct $\&$ to see any filling defect $\&$ patency of biliary tree.

\section{Results}

Total number of patients with gall stone disease participated in the study were 80 patients. Three patients were in the age group 18-29 year, two out of the three patients were known to had hereditary spherocytosis. In the age group 30-49 year there were 30(37.5\%) patients. In the oldest age group 50-69 year we had 47 patients constituted more than half of the sample $58.8 \%$ (Table-1). Female were $68(85 \%)$ and the remaining $12(15 \%)$ patients were male, with a female: male ratio of $(5.7: 1)$.

Table 1: Distribution of sample according to age group and gender

\begin{tabular}{|l|c|c|c|c|c|c|}
\hline \multirow{2}{*}{ Age group } & \multicolumn{3}{|c|}{ Patients } & \multicolumn{2}{c|}{ Total } \\
\cline { 2 - 7 } & \multicolumn{2}{|c|}{ Female } & \multicolumn{2}{c|}{ Male } & $\mathrm{n}$ & $\%$ \\
\cline { 2 - 7 } $18-29$ & $\mathrm{n}$ & $\%$ & $\mathrm{n}$ & $\%$ & 3 & 100 \\
\hline $30-49$ & 2 & 66.7 & 1 & 33.3 & 30 & 100 \\
\hline $50-69$ & 25 & 83.3 & 5 & 16.7 & 47 & 100 \\
\hline Total & 41 & 87.2 & 6 & 12.8 & 80 & 100 \\
\hline
\end{tabular}

Table 2 revealed the preoperative investigation done for the patients. Liver function test done for $7(8.7 \%)$ patients who are clinically jaundiced, all of them show abstractive jaundice (high total serum bilirubine $\&$ high direct bilirubin level with high serum alkaline phosphatase level).

plain radiology of abdomen was done for 40 patients. Rt-hypochondria radio-opaque shadow was seen in only $5(12.5 \%)$ of the cases. Two cases showed calcified GB wall.

Ultrasound study done for all patients, gallstones were present in (71) cases, while common bile duct stone was found only in (5) cases.

\begin{tabular}{|c|c|c|c|}
\hline Investigation & results & $\mathrm{n}$ & $\%$ \\
\hline \multirow{2}{*}{ Serum bilirubin $(n=80)$} & Jaundiced & 7 & 8.8 \\
\hline & Not jaundiced & 73 & 71.2 \\
\hline \multirow{3}{*}{$\begin{array}{l}\text { Plain abdomen X-ray } \\
(n=40)\end{array}$} & Radio-opaque shadow & 5 & 12.5 \\
\hline & Calcified gallbladder wall & 2 & 5.0 \\
\hline & Negative (normal) & 33 & 82.5 \\
\hline \multirow{5}{*}{$\begin{array}{l}\text { Ultrasound study } \\
(\mathrm{n}=80)\end{array}$} & Presence gall stone & 71 & 78.0 \\
\hline & Thick wall duct & 8 & 8.8 \\
\hline & Dilated common bile duct & 7 & 7.7 \\
\hline & Common Bile duct stone & 5 & 5.5 \\
\hline & Total* & 91 & 100 \\
\hline
\end{tabular}

Table 3 represented the type of surgery performed for the patients. Most of patient $60(75.0 \%)$ operated upon by open cholecystectomy. The gallstones in 18 patients $(22.5 \%)$ were removed by laparoscope.

Table 3: Type of operation performed

\begin{tabular}{|l|c|c|}
\hline Types of surgery & $\mathrm{n}$ & $\%$ \\
\hline Laparoscopic Cholecystectomy & 18 & 22.5 \\
\hline Open Cholecystectomy & 60 & 75.0 \\
\hline Laparoscopic Cholecystectomy converted into open cholecystectomy & 2 & 2.5 \\
\hline
\end{tabular}

Table 4 showed the main finding on exploring the abdomen via laparoscope or open surgery. The most common finding was inflammatory adhesion in 54 patients $(67.5 \%)$ of the total patients. Thick wall GB came next in 12 patients $(15 \%)$. Perforated GB was the least reported, only one patient $(1.3 \%)$. 
Table-4: Findings associated with or complicated gall stones disease according to the operative finding

\begin{tabular}{|c|c|c|}
\hline Types of complications & $\mathrm{n}$ & $\%$ \\
\hline Inflammatory adhesion & 54 & 67.5 \\
\hline Thick wall gallstone & 12 & 15 \\
\hline Gangrenous gallstone & 4 & 5.0 \\
\hline Empyema of gallstone & 6 & 7.5 \\
\hline Perforation of gallstone & 1 & 1.3 \\
\hline Very hard \& adherent gallstone & 4 & 5.0 \\
\hline Obstructed common bile duct by stone & 7 & 8.7 \\
\hline Silent gallstone disease & 14 & 17.5 \\
\hline Total* & 102 & \\
\hline
\end{tabular}

\section{Discussion}

Gall stones disease are common problem in our country. If not operated upon at proper time they end with complications (Balakrishnan et al. 2008).

Traditionary obese, older, females with multiple pregnancies, have a higher risk of developing gallstones (AlSaad et al. 2018). In this study there were some change in this trend of GS disease to a high incidence in non-obese female less than 50 years old $32.3 \%$ this could be attributed to the expansion in the use of contraceptive pills in some female, this agreed with Gupta study, also to multiple pregnancies in others (Gupta et al. 2008). Our study showed the rate of GS in female aged more than 50 years was $(51.3 \%)$ which is again comparable to the results of Gupta et al. 2008. There has also been a remarkable shift in the trend of gall-stone disease from middle aged, fertile, fat females to young asthenic females in their twenties (Sachdeva et al. 2011). There has been a significant increase in the incidence of gallstones in patient under 30s of age in the past 10 years also there is a change toward asthenic female (Abdul Hassan 2011).

The female to male ratio in our study was (5.7:1) which was higher than Gupta study where it was (4:1) (Gupta et al. 2008).

A higher prevalence of GS among females, observed in the current study, has been agreed with several studies (Farzaneh Sheikh Ahmad et al. 2007, Sun et al. 2009). Pregnancy and sex hormones are believed to be a causes for a higher risk, and this had been supported by several epidemiologic studies (Friedman et al. 1966, Barbara et al. 1987). The clinical relevance found by Agrusa et al (2014) is further broadened by the fact that the prevalence of gallstone disease increases with age.

In this study about (9) cases (11.3\%) pre-operative presented with acute cholecystitis, and (3) cases $(3.7 \%)$ with acute cholangitis biliary jaundice \& fever Charcot's triad. Silent gallstones were 14 cases (17.4\%). Abraham et al (2014) stated that gallstones are often discovered incidentally during ultrasonography or computed tomography of the abdomen. Only $10 \%$ to $20 \%$ of asymptomatic patients will eventually become symptomatic within five to 20 years of diagnosis.

Pain in abdomen, dyspepsia and jaundice were common presentation of patients in many studies (Pimpale et al. 2019).

According to the guideline forwarded by Pisano, laparoscopic cholecystectomy should be considered for all; the age, on its own, is not a contraindication for surgery (Pisano et al. 2019). While Nassar in his study found that age of the patient is a significant factor determining the likelihood of death and the length of hospital stay after any type of procedure of gallstones removal (Nassar \& Richter 2019). Laparoscopic and open cholecystectomy were used for our patients in this study, with a conversion from laparoscopic to open procedure at a rate of $2.5 \%$. this was less than the rate in Shrestha et al. (2014) study where it was (11.1\%), and less than the conversion rate of Pimpale et al. (2014) study (6.57\%).

Open method still common procedure done for our patients in current study this is probably due to lack in instruments and in some to low experience. This agree with Shrestha et al. (2014) study, who also reported several possible factors responsible for this conversion. These include age, sex, obesity, diabetes mellitus, acute cholecystitis, history of biliary diseases such as jaundice, cholangitis, history of pancreatitis (Shrestha et al. 2014).

Conversion to open surgery from laparoscopic cholecystectomy was encountered because of recurrent management of multiple episodes of acute cholecystitis and avoiding definitive surgery because of associated comorbidities. The conversion decision is considered as a sound judgment to avoid complications and reduce morbidity (Hussain et al. 2017).

\section{Conclusion}

Gallstones in our patients were more in female than male, there were some changes in the traditional presentation of patients toward less obese and younger age group. Many complications and clinical pictures associated with 
GS, some of them are serious other are even fatal. That is why cholecystectomy is highly indicated even for silent one.

Conflict of interest: None of interest

\section{References}

Balakrishnan, S., Samdani, T., Singhal, T., Hussain, A., Grandy-Smith, S., Nicholls, J., et al. (2008). Patient experience with gallstone disease in a National Health Service District Hospital. JSLS.12, 389-394.

Sachdeva, S., Khan, Z., Ansari, MA., Khalique, N., Anees, A. (2011). Lifestyle and Gallstone Disease: Scope for Primary Prevention. Indian J Community Med. 36(4), 263-267.

Nagral, S. (2005). Anatomy relevant to cholecystectomy. J Minim Access Surg. 1(2), 53-58.

Baiocchi, L., Zhou, T., Liangpunsakul, S., Lenci, I., Santopaolo, F., Meng, F., et al. (2019). Dual role of bile acids on the biliary epithelium: Friend or foe? Int. J. Mol. Sci. 20,1869

Reshetnyak, VI. (2012) Concept of the pathogenesis and treatment of cholelithiasis. World J Hepatol. 4(2), 18-34

Al-Saad, MH., Alawadh, AH., Al-Bagshi, AH., Al Ali, MH., Alshehab, AA., Alhodar, AA., et al. (2018) Surgical management of cholelithiasis. The Egyptian J of Hosp Med. 70(8), 1416-420

Singha, D., Pawar, NM., Prabhu, BJ., Kumar, N., Gopalarathnam, S. (2017). Prevalence of previously undiagnosed hypothyroidism in patients with cholelithiasis in a tertiary care center, North-East India. Int Surg J. 4, 932 35.

Yousif, HH. (2011) Relationship between serum levels of TSH and cholesterol with types of gallstones. Iraqi Postgraduate Med J. 10,7-12.

Cicala, M., Habib, F., Fiocca, F., Pallotta, N., Corazziari, E. (2001). Increased sphincter of Oddi basal pressure in patients affected by gall stone disease: a role for biliary stasis and colicky pain? Gut. 48, 414-17

Gupta, RL., Sharma, SB., Kumar, SP., Monika. (1998). "Changing trends (clinico-biochemical) in gall-bladder stone disease"- an observation. Indian J Med Sci. 52(7), 309-16.

Abdul Hassan, BA. (2011). Changing pattern and incidence of gallstone diseases in Al-Kadhymia Teaching Hospital. Iraqi j Med Sci. 9(2),179-83

Farzaneh Sheikh Ahmad, E., Zavvareh, HT., Gharadaghi, J., Sheikhvatan, M. (2007). Prevalence and characteristics of gallstone disease in an Iranian population: a study on cadavers. Hepatobiliary Pancreat Dis Int. 6, 509-12.

Sun, H., Tang, H., Jiang, S., Zeng, L., Chen, EQ., Zhou, TY., et al. (2009). Gender and metabolic differences of gallstone diseases. World J Gastroenterol. 15,1886-891.

Friedman, GD., Kannel, WB., Dawber, TR. (1966). The epidemiology of gallbladder disease: observations in the Framingham Study. J Chronic Dis. 19, 273-92.

Barbara, L., Sama, C., Morselli Labate, AM., Taroni, F., Rusticali, AG., Festi, D., et al. (1987). A population study on the prevalence of gallstones disease: the Sirmione Study. Hepatology. 7, 913-17.

Agrusa, A., Romano, G., Frazzetta, G., Chianetta, D., Sorce, V., Di Buono, G., et al. (2014). Role and outcomes of laparoscopic cholecystectomy in the elderly. Int J Surg.12(S2), S37-39.

Abraham, S., Rivero, HG., Erlikh, IV., Griffith, LF., Kondamudi, VK. (2014). Surgical and nonsurgical management of gallstones. Am Fam Physician. 89(10), 795-02

Pimpale, R., Katakwar, P., Akhtar, M. (2019). Cholelithiasis: causative factors, clinical manifestations and management. Int Surg J. 6(6), 2133-38.

Pisano, M., Ceresoli, M., Cimbanassi, S., Gurusamy, K., Coccolini, F., Borzellino, G. (2019). 2017 WSES and SICG guidelines on acute calculous cholecystitis in elderly population. World Journal of Emergency Surgery. 14,10

Nassar, Y. and Richter, S. (2019). Management of complicated gallstones in the elderly: comparing surgical and non-surgical treatment options. Gastroenterology Report. 7(3), 205-11

Shrestha, S., Shah, SS., Poudyal, S., Shah, JN., Jaiswal, VK. (2014). Conversion from Laparoscopic to Open Cholecystectomy. J of Patan Academy of H Sci. 1(1), 30-32

Hussain, GM., Bhat, SA., Khan, T., Want, MA., Mailk, AA., et al. (2017). Conversion of laparoscopic cholecystectomy to open cholecystectomy: An analysis in a high-risk group of patients. J Univer Surg. 5(3), 19 